\title{
8. Revisiting the poverty war: income status and financial stress among Indigenous Australians
}

\section{Boyd Hunter}

Australia is at war! First there were the history wars, as Henry Reynolds, Keith Windshuttle and others fought over the technical detail and interpretation of Australia's colonial history. Then came the war on terror, which followed the events of 11 September 2001. One of the latest 'wars' is the poverty war. Note that this is not the 'war on poverty' that LBJ talked about in the 1960s, but rather a battle for the hearts and minds of the Australian public (and media). Professor Peter Saunders has documented the Poverty wars that started with a coordinated series of skirmishes by the Centre for Independent Studies (CIS) against a report written for the Smith Family (Saunders 2005: 6-8). ${ }^{\text {l }}$ The debate started with some rather technical details of measurement, but quickly became bound up in questions of cause and response revealing stark differences in philosophy about choice, freedom, responsibility and the role of government. As always, the first casuality in war was the truth - or rather, public debate. The ferocity of the public debate caused the Smith family, one of the major non-profit welfare organisations in Australia, to stop using the word poverty and led them to disengage from poverty research. Saunders recommends that poverty research gets less technical and grounds itself in the lived experience of poverty and the social exclusion that perpetrates poverty in the long run (Saunders 2005). While I fully endorse this sentiment, it would largely entail qualitative research that has not yet been done, and is not possible to do using the 2002 NATSISS. However, the latest survey does provide direct information on financial stress and social capital for the first time. This provides an unambiguous advance in our knowledge of the processes underlying Indigenous disadvantage.

Income questions in the 2002 NATSISS tend to be asked in a reasonably similar way to other ABS surveys. The advent of financial stress questions in NATSISS and the GSS provide a broad indicator of how Indigenous and other Australian households are coping with their respective income statuses. Respondents were asked whether they could raise $\$ 2000$ within a week for something important. Note that the main social capital variables are dealt with in Ruth Weston and

1 That is, the Peter Saunders who happens to be an ARC Professorial Fellow, and had been a Director of the Social Policy Research Centre for many years. He is not to be confused with the Peter Saunders from the CIS. 
Matthew Gray (in this volume), with this chapter focusing largely on income characteristics and poverty issues.

The 1994 NATSISS included an impressive and diverse range of income data by source, as it asked respondents to indicate a separate amount for income from wages and salaries (for main job and second job), business income, government payments (that is, from a list of government pensions and a separate amount provided for family payments and rent assistance). ${ }^{2}$ Unfortunately, this rich source of information was not used by many researchers. One reason is that the publicly available data was coded into broad income ranges, so did not provide much distributional information. Another reason was that it was not entirely clear how robust the income data was. For example, was it really possible for individual respondents to accurately identify the separate amounts received from those sources when there were considerable flows between labour force states, and reasonably large flows between the various elements of the welfare system?

The official output for income for the 2002 NATSISS has been more modest than was attempted in the 1994 NATSISS (ABS 2004c). In contrast to the earlier survey, there has been no attempt to break down the amount of income from various sources in publications or the CURF. ${ }^{3}$ This is not necessarily a bad thing, as the analysts will not be tempted to overstate the amount of information contained in the income data. Indeed, the 2002 survey data has the major advantage that it is now provided in continuous form, and hence can be used for a more robust distributional analysis and a more informative analysis of poverty. ${ }^{4}$

The structure of this chapter is as follows. The next section elaborates on how the poverty war debate appears to have influenced the way the 2002 NATSISS data was presented in the official ABS publication $(2004 \mathrm{c})$ and reflects on the utility of their classification of 'low-income groups', which was used as a synonym for poverty in that publication. The discussion in this section will also reflect on the limitations of how the survey was conducted, with specific reference to the problems with how the questions on income and financial stress were asked. The third and fourth sections then examine new insights provided by NATSISS data with respect to income and financial stress. The concluding section reflects on future directions for research to consolidate the analysis in this chapter.

${ }^{2}$ While the income questions were asked slightly differently in CAs and NCAs, these minor differences are unlikely to matter much. Cash flow problems, and main source of income were not asked and not outputted for CAs. Note that information was collected and collated on the amount of income from separate sources in both CAs and non-CAs, but this data was not included in the CURF.

3 Note that there is still information on whether a person received income from various sources but there is no attempt to disaggregate the data.

4 Biddle \& Hunter (in this volume) show that censoring of income and housing costs data in the 2002 NATSISS is not an important issue, so it represents the best opportunity to date to get informative insights into Indigenous poverty. 


\section{Poverty wars and the ABS low income category}

The ABS is not a direct combatant in the poverty war. They are more like Switzerland, surrounded by belligerents. They are not doing the fighting but their policy appears to be affected by the war. Biddle and Hunter (in this volume) criticise the ABS's measure of 'low income' as misleading, and this section briefly re-visits that discussion and places it in the context of the poverty war.

Based on analysis of the non-Indigenous population, the ABS (2004c) outputs data for the second and third decile as a measure of 'low-income', arguing that the lowest income decile has characteristic closer to those with higher incomes. ABS (2004c) uses this 'low income' group as a synonym for poverty, which appears to be an implicit endorsement of CIS criticism of income-based measures in the poverty wars, especially the claim that measurement error (or, rather, under-reporting) is pronounced for low-income earners - particularly those who indicate they have an income less than or equal to zero. One reason to be cautious about adopting the ABS definition of 'low income' without question is that the self-employed - a group that are often associated with measurement error in their income status - are not prominent in the Indigenous population.

Even if it were true that income is not measured properly for the non-Indigenous population with very low income, Biddle and Hunter (in this volume) show that this assumption is suspect for the Indigenous population. Compared to those in the second and third decile, those in the first decile are significantly less likely to be employed and own or purchase a home, and significantly more likely to have fair/poor health. Other variables not reported here indicate that the bottom decile respondents are also more disadvantaged, as they are more likely to:

- have not completed Year 12

- be unemployed or outside the labour force

- have been arrested in the last year, and

- have transport difficulties.

The ABS definition of low income tends to understate the incidence of Indigenous disadvantage, and it should not be used.

In contrast to the 1994 NATSISS, there were no specific questions for self-employed people in the 2002 NATSISS. However, data was collected on whether there was income from 'profit or loss from own unincorporated business or partnership, rental property, dividends or interest'. Consequently, if one was particularly concerned about the reliability of income for the self-employed, one could eliminate people with some income from a business or partnership. Eliminating people with income from rental properties, dividends or interests might also be considered by analysts. While this strategy directly addresses the major criticism raised by the CIS in the poverty wars debate, it is not possible to implement using the CURF, as such data is not reported in remote areas. 
Notwithstanding this, the lack of any solid evidence that income is being measured incorrectly in the low income category means that one should not be overly concerned about such bias in the Indigenous data. However, any comparisons with non-Indigenous populations in the GSS should focus on non-remote areas in the NATSISS and eliminate potentially problematic respondents such as the self-employed to test the sensitivity of the analysis and to maximise the validity of Indigenous/non-Indigenous comparisons.

\section{Revisiting Indigenous income status and poverty}

Altman \& Hunter (1998) discuss how poverty among Indigenous people conceptually depends upon household composition, non-monetary income (produce from hunting and gathering activities), fundamental cross-cultural issues, and differences in consumer price indexes (CPIs) for various areas. One obvious issue for the financial stress variable is that $\$ 2000$ will have a different value for Indigenous groups in various parts of the country. Such issues are likely to be particularly pronounced for remote areas where hunting and gathering activities are prominent and the cost of living is likely to be high. ${ }^{5}$ Consequently, some caution needs to be exercised when comparing Indigenous financial stress in various parts of the country.

The National Academy of Sciences Panel on Poverty and Family Assistance in the United States of America (USA) undertook a major study measuring poverty in the 1990s. The main report concluded that, '[al]though the empirical evidence helps determine the limits of what makes sense, there is no objective procedure for measuring the different needs for different family types' (Citro \& Michael 1995).

While there is no objective basis for identifying the precise needs of families, it is still necessary to attempt to control for the different costs of households of differing size and composition. This is usually done by adjusting income using an 'equivalence scale'; for example, it is more expensive for two adults and three children to live in a household than a couple without dependants. Equivalence scales try to estimate how much more expensive it is for various households to live at a given standard of living, and consequently they vary with the number of people in the households and the mix of adults and dependants of various ages. The ABS calculated the 'equivalent income' by dividing the raw income by the Organization for Economic Cooperation and Development (OECD) scales, ranked this equivalised income for the whole population, and grouped households into quintiles (that is, groups of 20 percentiles of respondents, see ABS 2004c). However, the OECD scale is just one of many equivalence scales and I will discuss the range of feasible scales that could be used in the penultimate section.

${ }^{5}$ There is no regular, reliable data for CPIs outside the capital cities. 


\section{Income status and financial stress}

It will not surprise anyone that Indigenous people are twice as likely as other Australians to be in the lowest income quintile, and almost four times less likely to be in the highest quintile (see Table 8.1). Indigenous people are more likely than other Australians to rely on income from government pensions and allowances and be unable to raise $\$ 2000$ within a week for something important. This is consistent with Indigenous employment disadvantage and the fact that the mean income of Indigenous households is around 60 per cent of that of other households (for discussion of the former, see Chapman \& Gray in this volume).

\section{Table 8.1. Income summary by Indigenous status in non-remote areas, $2002^{\mathrm{ab}}$}

\begin{tabular}{|c|c|c|}
\hline & Indigenous & Non-Indigenous \\
\hline & $\%$ & $\%$ \\
\hline \multicolumn{3}{|l|}{ Equivalised household income } \\
\hline Lowest quintile & 41.7 & 19.3 \\
\hline Second quintile & 28.3 & 18.6 \\
\hline Third quintile & 14.4 & 19.0 \\
\hline Fourth quintile & 9.2 & 19.9 \\
\hline Highest quintile & 6.4 & 23.1 \\
\hline Main source of income CDEP & 10.9 & $\mathrm{~N} / \mathrm{A}$ \\
\hline Main source other wages & 30.6 & 56.9 \\
\hline Main source government pensions and allowances & 51.7 & 27.1 \\
\hline Unable to raise $\$ 2000$ within a week for something important & 54.3 & 13.6 \\
\hline Mean equivalised household income $(\$)$ & 394 & 665 \\
\hline
\end{tabular}

a. The population for this table is persons aged 18 and over.

b. All the differences between Indigenous and non-Indigenous statistics in this table are significant at the $5 \%$ level.

Source: Table 4 in ABS (2004c)

Table 8.2. Income summary by remoteness, 2002

\begin{tabular}{|c|c|c|c|}
\hline & Remote & Non- remote & Total \\
\hline & $\%$ & $\%$ & $\%$ \\
\hline \multicolumn{4}{|l|}{ Equivalised household income } \\
\hline Lowest quintile equivalised income & 40.5 & 43.2 & 42.5 \\
\hline Second quintile ${ }^{b}$ & 37.4 & 25.3 & 28.3 \\
\hline Third quintile & 12.8 & 14.5 & 14.0 \\
\hline Fourth quintile ${ }^{b}$ & 5.9 & 10.3 & 9.2 \\
\hline Highest quintile ${ }^{\mathrm{b}}$ & 3.5 & 6.7 & 5.9 \\
\hline Unable to raise $\$ 2000$ within a week for something important ${ }^{b}$ & 73.0 & 47.3 & 54.3 \\
\hline Mean equivalised gross household income $(\$)$ & 350 & 399 & 387 \\
\hline
\end{tabular}

a. The population for this table is Indigenous persons aged 15 and over.

b. The differences between remote and non-remote areas are statistically significant at the $5 \%$ level. Source: Table 1 in ABS (2004c)

The OECD equivalence scale does not take into account differences in the cost of living across areas, so it is particularly important to look at the income distributions and other characteristics in various areas. Table 8.2 documents the income differences in remote and non-remote areas and illustrates that the overall 
distributions are not very different: there is a similar proportion of residents in all quintiles, except the second, in which remote areas have 12 percentage points more. The bottom line, in the bottom line, is that the average equivalised income in remote areas is lower, albeit only slightly lower. However, the proportion of people who cannot raise $\$ 2000$ in a week for something important is much higher than in non-remote areas $(73.0 \%$ and $47.3 \%$ respectively). This may indicate that the cost of living is placing more financial stress in remote areas or that Indigenous people in remote areas do not have access to social networks from which they might borrow the money (i.e. a form of social capital). The latter possibility can probably be discounted, since Indigenous people often are said to have a substantial amount of bonding social capital (Hunter 2004b). While Indigenous people in remote areas tend to have large social networks, the 'problem of collective action' may mean that it is difficult to coordinate the large number of competing claims on group resources (Olson 1965).

Before moving onto poverty measures, I want to describe financial stress by labour force status and remoteness. Figure 8.1 presents the incidence of being able to raise $\$ 2000$ within a week in the bars. As in the rest of the monograph, the whiskers denote the 95 per cent confidence intervals, and as a rough rule if whiskers do not overlap, there is a significant difference between the estimates. As noted above, financial stress is higher in remote Australia. It is interesting to note that even non-CDEP employees in 'very remote' Australia have close to 60 per cent of workers suffering financial stress. This may reflect the methodology, with CAs being predominantly in such areas, but the size of the difference is remarkable and in my opinion unlikely to be explained by non-sampling error.

Figure 8.1. Financial stress by labour forces status and remoteness, 2002

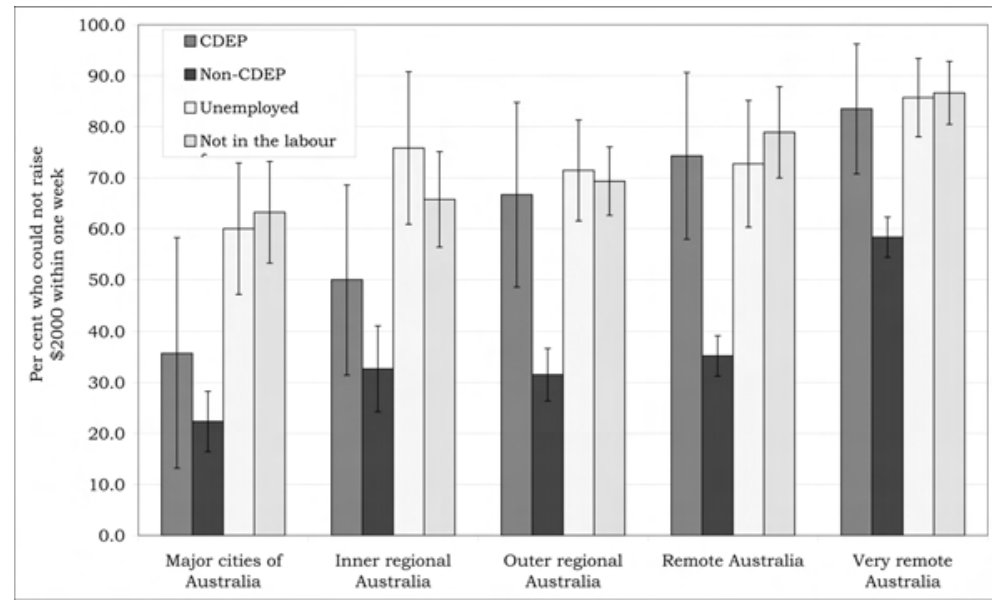

Source: Customised cross-tabulations from the 2002 NATSISS MURF. 
Also note that the level of financial stress is high for both unemployed and NILF categories in all areas. CDEP appears to have less financial stress in more urban environments but the reliability of these estimates is particularly low. That is, overall financial stress is high for all groups that are likely to be reliant on some form of government payment, and the best way out of financial stress is to have a job outside the CDEP scheme.

Table 8.3. Indigenous persons aged 15 years or over, selected income characteristics by remoteness, Australia, 2002

\begin{tabular}{|c|c|c|c|}
\hline & Remote & Non-remote & Australian tota \\
\hline & $\%$ & $\%$ & $\%$ \\
\hline \multicolumn{4}{|l|}{ Main source of personal income } \\
\hline $\mathrm{CDEP}^{\mathrm{a}}$ & 28.2 & 3.6 & 10.3 \\
\hline Other wages or salary ${ }^{a}$ & 18.1 & 33.2 & 29.0 \\
\hline Government pensions and allowances ${ }^{a}$ & 44.2 & 52.7 & 50.4 \\
\hline \multicolumn{4}{|l|}{ Access to money } \\
\hline Has a bank account ${ }^{a}$ & 87.0 & 96.9 & 94.2 \\
\hline \multicolumn{4}{|l|}{ Method(s) of accessing money ${ }^{a}$} \\
\hline Over the counter at a bank & 21.9 & 20.4 & 20.8 \\
\hline EFTPOS/ATM ${ }^{a}$ & 75.7 & 87.4 & 84.2 \\
\hline Internet banking ${ }^{a}$ & 1.1 & 6.1 & 4.7 \\
\hline Phone banking $^{\mathrm{a}}$ & 4.0 & 9.3 & 7.9 \\
\hline Over the counter at post office & 5.1 & 4.4 & 4.6 \\
\hline Other method & 2.2 & 2.3 & 2.3 \\
\hline
\end{tabular}

a. The difference between remote and non-remote statistics is significant at the $5 \%$ level.

Source: Table 18 in ABS (2004c)

It is possible to explore the differences between remote and non-remote areas in more detail by looking at selected income characteristics (table 8.3). Remote areas are more likely to report their main source of income as the CDEP scheme, but are less likely than other areas to rely for most of their income wages from other jobs or government pensions and allowances. The reason for this is simply that CDEP income is identified as a separate source of income. If one argues that $\mathrm{CDEP}$ is in some sense a government payment, albeit with a work requirement, then the reliance on government payments in remote areas is substantially higher than in other areas. Remote areas are substantially less likely than other areas to have had government pensions and allowances as their main source of income in the last two years, again presumably because of the flow of people through CDEP schemes.

How do Indigenous people access their money? People in remote areas are significantly less likely to have a bank account, access money over the counter or engage in internet banking. While the incidence of internet banking is much lower than for the rest of Australians in both areas, the particularly low level of internet banking in remote areas is due to the lack of access to personal computers and the internet in such areas (see Radoll in this volume). 
Table 8.4 explores several factors that are likely to be correlated with equivalised income. In the first CAEPR Working Paper, 'Three Nations Not One', I described how Indigenous respondents to the 1994 NATSISS only had a weak correlation between such factors and equivalent income. That study was hindered by the grouped nature of much of the income data for the 1994 survey, which meant that my calculations were only rough approximations.

Table 8.4. Indigenous persons aged 15 years or over, mean weekly equivalised gross household income quintiles by selected characteristics, Australia, 2002

\begin{tabular}{|c|c|c|c|c|}
\hline & \multicolumn{4}{|c|}{ Income quintiles } \\
\hline & Lowest & Second & Third & Fourth and fifth \\
\hline & $\%$ & $\%$ & $\%$ & $\%$ \\
\hline \multicolumn{5}{|l|}{ Self-assessed health status } \\
\hline Excellent/very good & 38.0 & 42.8 & 49.2 & 56.7 \\
\hline Fair/poor & 29.7 & 23.0 & 16.5 & 12.4 \\
\hline $\begin{array}{l}\text { Has a disability or long-term health } \\
\text { condition }\end{array}$ & 43.5 & 33.3 & 30.5 & 25.3 \\
\hline \multicolumn{5}{|l|}{ Risk behaviour/characteristics } \\
\hline Current daily smoker & 57.1 & 48.1 & 42.5 & 32.2 \\
\hline $\begin{array}{l}\text { Risky/high-risk alcohol consumption in } \\
\text { last } 12 \text { months }\end{array}$ & 13.8 & 14.4 & 15.5 & 14.0 \\
\hline \multicolumn{5}{|l|}{ Educational attainment } \\
\hline Has a non-school qualification & 17.8 & 23.4 & 38.1 & 43.0 \\
\hline \multicolumn{5}{|l|}{$\begin{array}{l}\text { Does not have a non-school } \\
\text { qualification }\end{array}$} \\
\hline Completed Year 12 & 5.9 & 11.1 & 12.1 & 19.4 \\
\hline Completed Year 10 or Year 11 & 30.5 & 31.1 & 28.4 & 23.5 \\
\hline Completed Year 9 or below & 45.7 & 34.5 & 21.4 & 14.1 \\
\hline Total with no non-school qualification & 82.2 & 76.6 & 61.9 & 57.0 \\
\hline \multicolumn{5}{|l|}{ Labour force status } \\
\hline \multicolumn{5}{|l|}{ Employed } \\
\hline CDEP & 9.3 & 17.8 & 11.5 & 3.4 \\
\hline non-CDEP & 8.9 & 33.6 & 61.5 & 84.8 \\
\hline Total employed & 18.1 & 51.4 & 73.0 & 88.2 \\
\hline Unemployed & 20.8 & 11.2 & 7.9 & 4.7 \\
\hline Not in the labour force & 61.0 & 37.3 & 19.1 & 7.1 \\
\hline \multicolumn{5}{|l|}{ Financial stress } \\
\hline $\begin{array}{l}\text { Unable to raise } \$ 2000 \text { within a week } \\
\text { for something important }\end{array}$ & 72.6 & 57.7 & 33.6 & 14.3 \\
\hline \multicolumn{5}{|l|}{ Law and justice } \\
\hline Arrested by police in last 5 years & 20.6 & 16.2 & 11.7 & 5.6 \\
\hline Incarcerated in last 5 years & 8.5 & 7.9 & 7.4 & 1.5 \\
\hline $\begin{array}{l}\text { Victim of physical or threatened } \\
\text { violence in last } 12 \text { months }\end{array}$ & 29.3 & 22.7 & 18.8 & 18.4 \\
\hline
\end{tabular}

Source: Table 9 in ABS (2004c)

The 2002 data, which permits a more robust estimate of equivalised income than was possible in 1994 (at least using the CURF), shows that there is a significant difference between long-term health in the first quintile and the other quintiles. However, the incidence of such conditions is still very high in the top income group, with over one quarter having a long-term health condition. This level of 
illness is unprecedented in other high income groups in Australia. Similarly, almost one third of the fourth and fifth quintiles were current daily smokers. All of the variables in this table exhibit a significant difference between the bottom quintile and the fourth and fifth quintiles except risky alcohol consumption, which is slightly higher in the top income group. Indigenous people in the bottom quintile are significantly less likely than the top income group to have an educational qualification, be employed outside the CDEP scheme, or participate in the labour force. However, they are more likely to be in financial stress, and to have been arrested, incarcerated or a victim of physical or threatened violence.

Does the fact that 15.6 per cent of Indigenous people are in the top two quintiles of Australian household income (see Table 8.1) - and that these people appear to be somewhat better off than other Indigenous people - mean there is now an Indigenous 'middle class'? While there may be some signs of an Indigenous middle class emerging, the rates of social ills and socioeconomic disadvantage are too high for the 'rich' groups in Table 8.4. Obviously, addressing income levels is not the only relevant policy. In spite of the conclusion reached, it is clear that one of the main correlates of high income status is securing a non-CDEP scheme job, and addressing Indigenous labour market disadvantage is likely to be the most effective policy emphasis.

\section{A brief digression on validating the top-coding assumptions when using grouped income data for Indigenous people}

NATSISS allows us to accurately benchmark the top-coding assumptions routinely used in analysis of grouped data in the respective censuses. In the absence of other data, researchers and policy-makers tend to assume that the average income in the top category is some multiple of the bottom end of the income range, usually a factor of around 1.5. The mean income for the 2002 NATSISS respondents in the top category used in the 2001 Census can be calculated to verify the accuracy of this assumption for Indigenous Australians. ${ }^{6}$ The appropriate multiple of the bottom income range is 1.19 for remote areas and 1.32 for non-remote areas. Therefore, the usual assumptions were far too high for Indigenous people, especially in remote areas, which means previous estimates of average income will tend to understate Indigenous income disadvantage.

\footnotetext{
6 The income category was adjusted for the weighted average of CPIs in Australian capital cities for the
} relevant period. 


\section{Indigenous and other Australian poverty in 2002}

The basic measure of poverty is the headcount measure which can be used to illustrate the disadvantage of Indigenous Australians (that even the researchers at the CIS acknowledge). Table 8.5 presents the headcount measures calculated using a poverty line based on one half of the median equivalised income within the GSS. This was considered to be a reasonably robust poverty line by both sides of the poverty war debate. In one-family households, Indigenous people are twice as likely to be under the poverty line. In households with more than one family living in the dwelling, Indigenous people are over 14 times more likely to be classified as poor. Clearly, household structure is an important 'driver' of Indigenous poverty. The equivalence scales used to calculate equivalent income is defined on household structure, so the poverty rates are in a sense 'driven' by household structure.

Table 8.5. Proportion with less than $\mathbf{5 0}$ per cent of median equivalised household income

\begin{tabular}{lrr}
\hline & Indigenous & All Australian \\
\hline One family household & 41.8 & 17.29 \\
More than 1 family household & 42.5 & 3.0 \\
No dependants & 41.2 & 23.6 \\
1 dependant in household & 39.1 & 12.6 \\
$2-4$ dependants in household & 44.7 & 16.1 \\
$5+$ dependants in household & 64.9 & 53.9 \\
Major cities & 39.3 & 17.9 \\
Inner regional & 50.2 & 23.7 \\
Outer regional & 46.1 & 27.0 \\
Remote/very remote & 43.3 & $\mathrm{NA}$ \\
\hline
\end{tabular}

Source: Customised cross-tabulations from the 2002 NATSISS and GSS RADL

Having a large number of dependants is another recipe for being in poverty for both Indigenous and non-Indigenous people (i.e. having five or more dependants). Having said this, poverty is also particularly pronounced in Indigenous households with only one dependant.

The variation in poverty by geography is particularly interesting. While poverty is lowest for Indigenous and other Australians in major cities, it is particularly high for Indigenous people living in inner regional areas. Therefore, remote areas are actually less poor than in regional and provincial areas. Despite the lack of an estimate for remote areas from the GSS, poverty for all Australians tends to increase as accessibility to services becomes more difficult.

The tension between the poverty estimates in Table 8.5 and the financial stress data in Figure 8.1 and Table 8.2 is worth noting. Financial stress is higher in remote areas, especially very remote areas. It is particularly noteworthy that non-CDEP scheme employment in very remote areas is also associated with high levels of financial stress. Given that this group is likely to be among the better 
educated (and most acculturated), this result is unlikely to be caused solely by non-sampling error. The tension between this direct question on financial stress and the standard measures of poverty means that we should question the latter, which are indirectly measured using a series of assumptions.

The theory of poverty is related to utility functions which are used to derive weights for particular households based on cost structures implicit in expenditure surveys (see Hunter, Kennedy \& Biddle 2004). Underlying cost structures (and indeed preferences) are not necessarily the same for all sub-population groups, and therefore the imposition of the OECD equivalence scales on NATISS data can - and should - be contested. That is, the following question must be asked: how valid are the OECD equivalence scales when measuring Indigenous poverty?

In technical terms, equivalence scales estimate the 'economies of scale' of living in houses of various sizes and composition. The feasible range of equivalent incomes is bound by raw income and per capita income, with the latter representing an equivalence scale where the cost of each extra person is the same of those currently living in the house. At the other extreme, the equivalence scale underlying raw income assumes that each extra person living in a household cost nothing (i.e. perfect economies of scale). The OECD scale is somewhere between these two extreme assumptions.

Table 8.6 documents the headcount measure of poverty estimated by the proportion of people in households that are classified as poor using the various equivalence scales. Where there is only one person in the household, the actual equivalent income should not change when moving from raw income to per capita income, but the rest of the distribution does change which, in turn, results in a change to the poverty line. Consequently, per capita income pushes such households up the income distribution and they appear less poor. For households with two or more people in them, both the poverty line and the household's equivalent income changes.

Table 8.6. Scoping the feasible range of equivalence scales: proportion with less than $\mathbf{5 0}$ per cent of median household income, 2002

\begin{tabular}{lrrr}
\hline & Per capita income & $\begin{array}{r}\text { Equivalised household } \\
\text { income }\end{array}$ & Raw household income \\
\hline Indigenous & 15.21 & 70.08 & 81.55 \\
1 person in household & 35.36 & 37.78 & 40.11 \\
2-4 persons in household & 65.09 & 47.64 & 10.45 \\
5 + persons in household & & & \\
All Australian & 6.44 & 44.79 & 62.44 \\
1 person in household & 11.92 & 17.06 & 20.68 \\
2-4 persons in household & 22.98 & 13.73 & 5.38 \\
5 + persons in household & & & \\
\hline
\end{tabular}

Source: Author's calculations based on the 2002 NATSISS and GSS RADL 
It is particularly interesting to note that Indigenous households with between two and four people in them have a tight range of poverty estimates, so we can be reasonably confident that these poverty estimates are reliable irrespective of the equivalence scale used. However, the story is different for large households with over five people in them, as poverty estimates vary wildly for both Indigenous and other Australians. This is not a criticism of the ABS because this has been observed earlier by many authors (Hunter, Kennedy \& Biddle 2004; Whiteford 1985). The main point is that measured poverty in Table 8.6 is particularly sensitive to the choice of equivalence scales for large households, which Indigenous people frequently live in.

\section{Concluding remarks}

This chapter has attempted to illustrate that technical details do matter in poverty measurement because there is an implicit equivalence scale underlying Australia's welfare system. The choice of an appropriate equivalence scale(s) for Indigenous Australians needs to be scrutinised and researched so that Indigenous poverty and disadvantage can be addressed adequately.

Where to for future research? The RADL offers exciting potential for research, especially given the more useful continuous income data and financial stress indicators. For my part, I have not published much serious econometric research on predictors of income using the 1994 NATSISS because the grouped nature of that data obscured too much information (one possible exception was some incidental analysis that was conducted to test sensitivity of other analysis in Borland \& Hunter 2000). The addition of continuous income data on the RADL for the 2002 NATSISS means that more conventional labour market analysis of Indigenous wages is warranted.

Another potential area for research is that the simultaneous collection of GSS and NATSISS data offers the opportunity to examine the nature of Indigenous disadvantage vis-à-vis other Australians. It would be particularly interesting to pool the NATSISS and GSS data, but that could only be done within the confines of the ABS. One important impediment to the power of any such analysis is that there does not appear to be an Indigenous identifier on the GSS RADL, which means it is not possible to directly calculate non-Indigenous estimates. The inability to compare Indigenous estimates from the NATSISS to non-Indigenous estimates in the GSS is a major weakness of the set-up of the GSS CURF and severely circumscribes the usefulness of both data sets for policy-makers. 